\title{
Le bras (cassé) de la science
}

\section{Christophe Didier}

\section{(2) OpenEdition}

Journals

Édition électronique

URL : http://journals.openedition.org/rbnu/1531

DOl : $10.4000 /$ rbnu. 1531

ISSN : 2679-6104

\section{Éditeur}

Bibliothèque nationale et universitaire de Strasbourg

\section{Édition imprimée}

Date de publication : 1 mai 2016

Pagination : 80-81

ISBN : 9782859230623

ISSN : 2109-2761

\section{Référence électronique}

Christophe Didier, «Le bras (cassé) de la science », La Revue de la BNU [En ligne], 13 | 2016, mis en ligne le 01 mars 2020, consulté le 10 décembre 2020. URL : http://journals.openedition.org/rbnu/1531 ; DOI : https://doi.org/10.4000/rbnu.1531

\section{c) (i)(2)}

La Revue de la BNU est mise à disposition selon les termes de la Licence Creative Commons Attribution - Pas d'Utilisation Commerciale - Partage dans les Mêmes Conditions 4.0 International. 

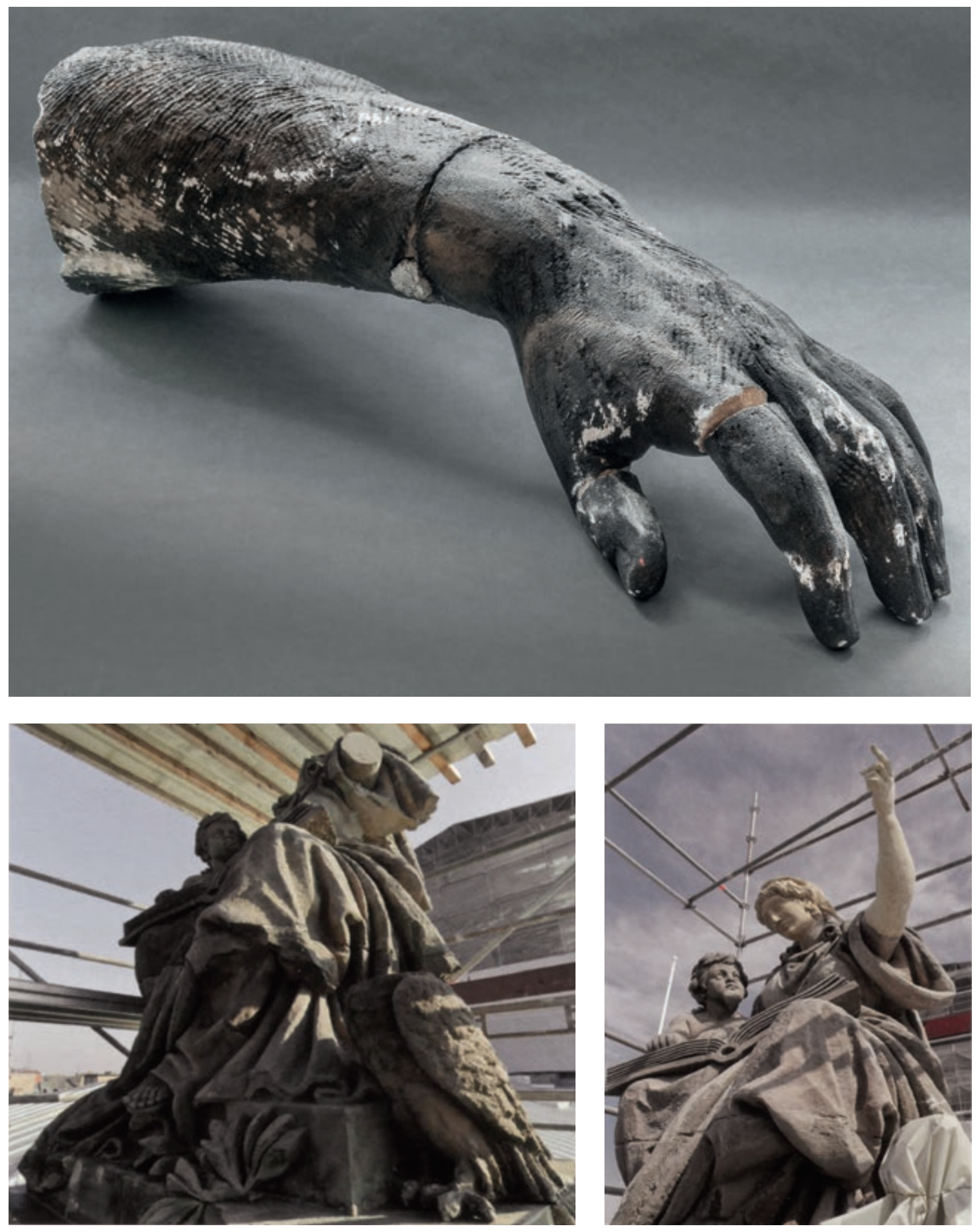

Allégorie de la science avant et après sa restauration 


\section{LE BRAS (CASSÉ) DE LA SCIENGE}

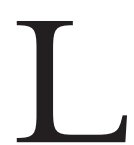

ors du chantier de restructuration de la Bibliothèque nationale et universitaire de Strasbourg, entre 2010 et 2014, les façades du bâtiment, classées monument historique, furent intégralement restaurées. Pour les parties latérales et arrière, on se contenta d'un nettoyage et d'un ravalement, les crédits disponibles ne permettant pas de restauration à l'identique des éléments de sculpture abîmés. Il n'en fut heureusement pas de même pour la façade principale, formant avec ses retours nord et sud un avant-corps particulièrement décoré. Dans ce cas, toutes les sculptures et éléments décoratifs (pots à feu, palmettes, frises, etc.) furent restaurés à l'identique, avec remplacement des parties manquantes ou trop fortement abîmées si nécessaire. Ce chantier aboutit en particulier à la dépose et à la reconstitution du bras levé de l'allégorie de la science qui domine, avec son pendant représentant les arts, le fronton de la façade principale. Trop abîmé pour être laissé en l'état, mais jugé suffisamment explicite, comme élément sculpté, pour témoigner de la mémoire artistique et architecturale du bâtiment, le puissant bras de grès a donc été déposé dans une des réserves de la bibliothèque.

Il ne s'agit pas ici de retracer l'aventure de la conception du programme iconographique de ce qui était jadis la Kaiserliche Universitäts- und Landesbibliothek et de son environnement - programme qui se conçoit d'ailleurs comme un ensemble, un bâtiment répondant à l'autre et chacun devant faire montre de ses spécificités. Rappelons seulement que les statues de l'avant-corps de la bibliothèque, fonctionnant à la fois comme une invite (le bras levé) et comme autant de symboles, ont leur équivalent, par exemple, au Palais universitaire et, sur la même place de la République, dans le bâtiment voisin du Parlement régional (l'actuel Théâtre national de Strasbourg). C'est d'ailleurs le même sculpteur, le Badois Johann Baptist Riegger (1855-1916) qui fut chargé de l'exécution de l'ensemble du programme des deux bâtiments de la place (après que ce furent les mêmes architectes, Hartel et Neckelmann, qui les eurent construits). La conception initiale de celui de la bibliothèque avait été élaborée au plus haut niveau, le professeur Adolf Michaelis ayant été chargé de faire les premières propositions dès 189o, et le directeur Karl August Barack étant ensuite en relations à ce sujet avec les autorités administratives comme universitaires. C'est donc aussi le témoignage d'une politique intellectuelle autant qu'urbanistique que l'on a choisi de conserver avec ce bras de grès de la science. Il a rejoint dans les réserves de la BNU d'autres témoignages, peints ou sculptés, de l'activité de l'établissement, comme les portraits des directeurs successifs Barack ou Euting, ou encore le buste de marbre du bibliothécaire Gustav Mühl.

\section{Christophe Didier}

Pour plus de renseignements sur le programme sculpté de la bibliothèque, sa genèse et sa signification, voir en particulier :

- Didier, Christophe, «Science et politique : le message de pierre de la Bibliothèque nationale et universitaire de Strasbourg ", in La Revue de la BNU, $\mathrm{n}^{\circ}$, printemps 2010

- Métamorphoses : un bâtiment, des collections / sous la dir. de Christophe Didier et Madeleine Zeller, Strasbourg, BNU, 2015

- Nohlen, Klaus, Construire une capitale. Strasbourg impérial de 1870 à 1918. Les bâtiments officiels de la Place Impériale, Strasbourg, Société savante d'Alsace, 1997

- Zimmermann, Till, Une nouvelle bibliothèque à la fin du XIXe siècle : la conception et la réalisation de la Bibliothèque impériale de l'Université et du Land à Strasbourg (18701895), mémoire de l'Université de Strasbourg, 2004 